\title{
Microencapsulation of nanoemulsions: novel Trojan particles for bioactive lipid molecule delivery
}

This article was published in the following Dove Press journal:

International Journal of Nanomedicine

23 June 2011

Number of times this article has been viewed

\author{
Xiang $\mathrm{Li}^{\prime}$ \\ Nicolas Anton' \\ Thi Minh Chau Ta' \\ Minjie Zhao ${ }^{2}$ \\ Nadia Messaddeq ${ }^{3}$ \\ Thierry F Vandamme \\ 'University of Strasbourg, Faculty \\ of Pharmacy, UMR CNRS 7I99 \\ Laboratory of Conception and \\ Application of Bioactive Molecules \\ (Biogalenic Pharmacy team); \\ 2University of Strasbourg, Faculty of \\ Pharmacy, CNRS UMR 7I78, IPHC, \\ Laboratory of Analytic Chemistry \\ and Food Science; Institute of \\ Genetics and Molecular and Cellular \\ Biology (IGBMC), UMR University of \\ Strasbourg/CNRS/INSERM/Collège \\ de France, Illkirch, France
}

Background: Nanoemulsions consist of very stable nanodroplets of oil dispersed in an aqueous phase, typically below $300 \mathrm{~nm}$ in size. They can be used to obtain a very fine, homogeneous dispersion of lipophilic compounds in water, thus facilitating their handling and use in nanomedicine. However, the drawback is that they are suspended in an aqueous media. This study proposes a novel technique for drying lipid nanoemulsion suspensions to create so-called Trojan particles, ie, polymer microparticles (around $2 \mu \mathrm{m}$ ) which very homogeneously "entrap" the nano-oil droplets (around $150 \mathrm{~nm}$ ) in their core.

Methods: Microencapsulation of the nanoemulsions was performed using a spray-drying process and resulted in a dried powder of microparticles. By using a low-energy nanoemulsification method and relatively gentle spray-drying, the process was well suited to sensitive molecules. The model lipophilic molecule tested was vitamin E acetate, encapsulated at around $20 \%$ in dried powder. Results: We showed that the presence of nanoemulsions in solution before spray-drying had a significant impact on microparticle size, distribution, and morphology. However, the process itself did not destroy the oil nanodroplets, which could easily be redispersed when the powder was put back in contact with water. High-performance liquid chromatography follow-up of the integrity of the vitamin $\mathrm{E}$ acetate showed that the molecules were intact throughout the process, as well as when conserved in their dried form.

Conclusion: This study proposes a novel technique using a spray-drying process to microencapsulate nanoemulsions. The multiscale object formed, so-called Trojan microparticles, were shown to successfully encapsulate, protect, and release the lipid nanodroplets.

Keywords: nanoemulsions, microparticles, Trojan particle, spray-drying, low-energy emulsification, vitamin E acetate

\section{Introduction}

Microencapsulation processes are generally used for both isolating and protecting sensitive substances or bioactive molecules and facilitating their controlled release. ${ }^{1}$ The formulation of microparticles is generally tailored to suit the target administration route. Microparticles can be built with a core/shell structure composed of two materials, ie, so-called "core materials" and "wall materials". Active ingredients are either entrapped in the core materials, or form the core material itself, enclosed and protected by the wall material. The different formulation processes used to produce microparticles are divided into three groups, 1) chemical methods, eg, polymerization or interface polycondensation; 2) physicochemical methods, such as coacervation, solvent diffusion, solvent evaporation, phase separation, or rapid expansion of supercritical fluids; and 3) physicomechanical methods, including spray-drying, fluidized-bed technology, or pan coating. ${ }^{2}$ In this paper, we focus on the third group of methods and notably 
on use of the spray-drying process in the formulation of microparticles. Spray-drying is a widely used technology for microencapsulation in the food and pharmaceutical industries. The process rapidly converts a liquid (which can be a solution, a suspension, or an emulsion) into a dried powder. Core materials, homogeneously solubilized or dispersed in an aqueous media, are sprayed in contact with a hot gas flux. The sprayed droplets are still quite small, ranging from a few to a few hundred micrometers, thus developing a large air/ water interface area, resulting in effective heat transfer. As a result, the droplets are rapidly evaporated and dehydrated to form dried solid particles. The drying process is complete when the temperature of the particle is equal to that of the air. ${ }^{3}$ At this point, the active ingredients appear homogenously dispersed in the matricial, dried, microparticulate structure. ${ }^{4}$ Spraying and drying the particles is a rapid process, performed within a few seconds. It is this speed that makes the process suitable for use with sensitive or thermosensitive compounds without resulting in their degradation. When this process is performed with biodegradable and biocompatible wall materials, and with adapting the particle sizes and densities to the administration route, spray-drying has been shown to be suitable for the inhalation route ${ }^{5,6}$ and intraocular administration. ${ }^{7}$ The solid forms generated can also be used to make tablets or capsules for oral administration, enhancing intestinal absorption and bioavailability. The nature of the solid formed helps increase the stability of compounds liable to oxidize in solution.

The spray-drying process produces relatively monodispersed particles with high encapsulation rates. Such micrometric systems present many advantages for pharmaceutical applications, such as easy manipulation and administration of the microparticles, for instance, and reduced clearance after subcutaneous or intraocular administration. However, a major disadvantage is their low penetration and diffusion in the tissues. To counter this problem, these microsized carriers encapsulate the nanoparticles capable of doing the job. These multiscaled systems are known as "Trojan" particles.

When dried or in suspension, nanoparticles are not usable due to their low stability, aggregation, and hydrolysis in water. Their manipulation is greatly improved when encapsulated in the aforementioned Trojan systems. However, to date, only recent work proposes such formulations, using only polymeric nanoparticles..$^{7-9}$ Although used as drug carriers, these polymeric nanoparticles present ongoing drawbacks due to the polymers themselves, which limit the drug encapsulation rates or leave polymeric residues in living tissues. The innovative concept of our work here is the creation of
Trojan microparticles by spray-drying and encapsulation, not of polymeric nanoparticles but of nanoemulsions, which are fundamentally different systems. For pharmaceutical applications, nanoemulsions undoubtedly present numerous advantages in comparison with polymeric nanoparticles. For thermodynamic reasons, nanoemulsions prove to be extremely stable systems not only in suspension before spraydrying, but also when the droplets are conserved through the process in water after dissolution of the powder. The core of the droplet is often only made up of active ingredients (as is the case here), and thus the encapsulation rates and yields need to be a few orders of magnitude higher than for polymeric nanoparticles. For instance, Gomez-Gaete et $\mathrm{al}^{7}$ encapsulated bioactive hydrophobic molecules of dexamethasone at nanoparticle encapsulation rates as low as $0.7 \%$, and when the optimized solubilization of lipophilic compounds in oils increased, this rate and the direct emulsification of liquid lipids gave a full encapsulation of $100 \%$. Such innovative Trojan particles also provide solutions for drying lipids or lipophilic bioactive molecules, and their nanoscaled formulation increases and optimizes their bioavailability at the administration site. The major potential problem concerning microencapsulation of nanoemulsions, which we propose to address here, is conservation of the nanoemulsion structure and size distribution throughout the spray-drying process.

Nanoemulsions are generally defined as oil-in-water emulsion droplets, with a size ranging in the nanometric scale, typically $20-300 \mathrm{~nm} \cdot{ }^{10-12}$ Owing to their very small size, nanoemulsions have great stability for up to several months. The reasons for this stability are well documented in the literature, ${ }^{13-15}$ and originate in the unlikeliness of the droplets to flocculate and coalesce. The only process of destabilization is by Ostwald ripening. As a result, nanoemulsions can be used as a new tool for chemical and pharmaceutical applications, for instance providing a homogeneous dispersion of otherwise poorly soluble materials in water. Nanoemulsions can be used as nanocarriers for drugs or contrast agents in the applications of targeting and controlled delivery. As regards the formulation processes for nanoemulsions, they can be divided into two groups, ie, high-energy and low-energy methods. ${ }^{13,14}$ High-energy methods use specific devices to form nanoemulsions, such as high-pressure homogenizers or ultrasound generators, whereas low-energy methods make the most of the intrinsic physicochemical properties of the components in the formulation to attain the nanometric range. In this case, nanoemulsions are formed spontaneously at room temperature. ${ }^{14}$ In our work, we have chosen to use low-energy methods, which are also both solvent-free and 
polymer-free, for the generation of a definitively stable oil suspension dispersed in an aqueous phase. ${ }^{13-15}$

It is worth noting the many studies done on microencapsulating of emulsions using spray-drying. ${ }^{16-22}$ However, the objectives and scope of these published works are restricted to the drying of oily or fatty species, and do not deal with the conservation of the structure (eg, size) of the dispersed system or emulsified forms. That is precisely why these studies only concern conventional "macro emulsions" (ie, with a mean diameter of over $1 \mu \mathrm{m}$ ). Recent works have reported very efficient methods obtaining up to $90 \%$ of oil content in the dried powder. ${ }^{23}$ However, the emulsion droplet size plays an important role in the encapsulation efficiency during spray drying, ${ }^{16-18}$ ie, the smaller the size of the encapsulated emulsion, the more efficient the encapsulation. In this respect, the microencapsulation of nanoemulsions can further enhance the result without using specific interface crosslinking technology. ${ }^{23}$

Returning to the main objective, ie, the formulation of Trojan particles, our aim is to conserve the nanometric scale of the encapsulated droplets entrapped in the microparticles and to ensure their delivery, with resolubilization of the dried microparticle powder in water. In this work, we present a new methodological approach showing microencapsulation of nanoemulsions. This should open new doors for the application of these simple and promising nanoparticulate systems. Low-energy nanoemulsification methods performed at room temperature, associated with the gentle process of spray-drying, make the whole formulation process suitable for encapsulation of sensitive molecules. In this study, we used a formulation with vitamin E acetate as the model lipophilic molecule to be encapsulated. This molecule constitutes the hydrophobic phase of the formulation and, consequently, the nanoemulsion core was made up exclusively of vitamin $\mathrm{E}$ acetate. The sample characterization was obtained by scanning electron microscopy (SEM), and the particle size distributions were worked out by analyzing the SEM pictures, thus allowing a quantitative comparison of the powders. The microencapsulation process was first evaluated as a function of the various formulation parameters, such as the nature of the wall materials and the concentration in solution before spray-drying. These preliminary results subsequently allowed us to optimize the microencapsulation of a vitamin $\mathrm{E}$ acetate nanoemulsion. A number of biodegradable polymers were evaluated for use as wall materials in the process, namely, gum arabic, whey protein, polyvinyl alcohol, modified starches, maltodextrin, hydroxypropyl beta cyclodextrins, and pregelatinized hydroxypropyl pea starch. The stability of the nanoemulsions was controlled throughout the process by dynamic light scattering, and the integrity and stability of vitamin $\mathrm{E}$ acetate molecules was followed for 3 months using high-performance liquid chromatography (HPLC).

\section{Methods and materials Materials}

Vitamin E acetate (DL-alpha-tocopheryl acetate) was purchased from Sigma (St Louis, MO). Nonionic surfactants from BASF (Ludwigshafen, Germany), ie, Cremophor ELP $^{\circledR}$ (polyoxiethylated-35 castor oil, hydrophilic-lipophilic balance approximately 12-14) were kindly provided by Laserson (Etampes, France), and used as received. The wall materials selected were gum arabic (CNI Colloides Naturels International, Rouen, France), whey protein (Davisco Foods International Inc, Eden Prairie, MN), Cleargum ${ }^{\circledR} \mathrm{CO} 03$ (modified starch, Roquette, Lestrem, France), Glucidex ${ }^{\circledR}$ IT 12 (maltodextrin, DE 12, Roquette), polyvinyl alcohol (PVA, Sigma), Kleptose ${ }^{\circledR}$ HPB Parenteral Grade (hydroxypropyl beta cyclodextrins, Roquette), Nutriose ${ }^{\circledR}$ FB 06 (modified starch, Roquette), and Lycoat ${ }^{\circledR}$ RS 780 (pregelatinized hydroxypropyl pea starch, Roquette). Finally, Ultrapure water was obtained using the MilliQ ${ }^{\circledR}$ filtration system (Millipore, Saint-Quentin-en-Yvelines, France).

\section{Sample preparation}

The samples were composed of nanoemulsions dispersed in an aqueous solution to dissolve the wall materials. Vitamin E acetate nanoemulsions were selected as model suspensions with a controllable size and polydispersity. The size range chosen was suited for microencapsulation. Nanoemulsions were formulated according to the low-energy emulsification process described elsewhere. ${ }^{14}$ In short, nanoemulsion droplets were spontaneously formed after bringing the two phases into contact. The first was composed of vitamin $\mathrm{E}$ acetate (the oily phase) plus the hydrophilic surfactant, both totally miscible in each other and gently homogenized at room temperature, and the second phase was pure water. Once these two liquid phases were mixed, the hydrophilic species were immediately solubilized by the aqueous phase, inducing the demixing of the oil (through spinodal decomposition) in the form of nanometric emulsion droplets. Surfactants immediately stabilized the nanoemulsion droplets formed. Vitamin E acetate was chosen as a model oily phase, mixed with the nonionic surfactants, and then brought into contact with the aqueous phase, thus generating nanoemulsions. The spontaneous emulsification processes were characterized, as described previously, ${ }^{14}$ by following 
the impact of the surfactant oil weight (SOW) ratio $\left(w_{\text {surfactant }}\right.$ ! $\left.\left[w_{\text {surfactant }}+w_{\text {oil }}\right] \times 100\right)$ on both the hydrodynamic diameter and polydispersity index. The optimized formulation is a compromise between nanoemulsions presenting a good monodispersity, a size in the nanometric range, and the lowest possible amount of surfactant. The water added for the generation of nanoemulsions influences neither their physicochemical properties nor their size and polydispersity index. Thus, the SOW ratio was fixed at $40 \%$ for all the formulations $\left(\left[w_{\text {surfactant }}+w_{\text {oil }}\right] /\left[w_{\text {surfactant }}+w_{\text {water }}+w_{\text {oil }}\right] \times 100\right)$. The size distribution and polydispersity of the nanoemulsions were assessed by dynamic light scattering using a Malvern Nano ZS ${ }^{\circledR}$ instrument (Malvern, Orsay, France). A heliumneon laser $(4 \mathrm{~mW})$ was operated at $633 \mathrm{~nm}$ with the scatter angle fixed at $173^{\circ}$, and the temperature was maintained at $25^{\circ} \mathrm{C}$. The polydispersity index is a measure of the broadness of the size distribution derived from the cumulative analysis of dynamic light scattering. For a single Gaussian population with standard deviation $\sigma$, and mean size $x_{P C S}$, then the polydispersity index $=\sigma^{2} / x_{P C S}^{2}$ is the relative variance of the distribution. The polydispersity index indicates the quality of the dispersion, from values lower than 0.1 for acceptable measurements and good quality colloidal suspensions, to values close to 1 for poor quality samples, either with droplet sizes out of the colloidal range or with a very high polydispersity. Measurements were performed in triplicate, before and after the spray-drying process (filtered at $0.45 \mu \mathrm{m}$ in the above case).

As regards the polymers used as wall materials, these were dissolved and swelled in ultrapure water 1 day prior to performing the experiments. The amount of wall material and its impact on the spray-dried particles was studied, as were the respective proportions of core and wall materials which also appear to be an important parameter of the formulation. These parameters were studied and optimized in order to incorporate the highest possible amount of oil with the dried, powdery aspect of the samples. The wall material solution was incorporated in the nanoemulsions of vitamin $E$ acetate under stirring until a homogenous suspension was obtained.

\section{Spray-drying}

The liquid suspensions were atomized into powders by the Büchi Mini Spray dryer B-290 (Flawil, Switzerland). The two-fluid nozzle dispersed the liquid suspensions into thin droplets, which were heated in the drying chamber. The droplets were instantly transformed into a dry powder. The speed of the process is acknowledged as being well suited to the spray-drying of sensitive or thermosensitive molecules.
The operational conditions were as follows: aspiration rate $100 \%$; inlet temperature $150^{\circ} \mathrm{C}$; and solution feed rate $10 \mathrm{~mL} / \mathrm{minute}$. The spray-dried powders were kept at room temperature in a closed flask.

\section{Scanning electron microscopy and size distributions}

The size distribution and morphology of the spray-dried microparticles were evaluated by SEM (Philips XL20, University of Strasbourg; Philips, Amsterdam, the Netherlands). The specimen was fixed on a carbon support, coated with a palladium layer, and analyzed at $20 \mathrm{kV}$. The particle size distributions were analyzed from SEM micrographs using a software-assisted method previously developed in our laboratory and already described elsewhere. ${ }^{24}$ The exact number of particles and their diameters were calculated from raw images, even for agglomerated particles. Hence, even if particles form aggregates, our method isolates each particle from the rest and defines its surface area, thus allowing individual identification and disclosing the particle size distribution. A log-normal extrapolation was applied, with a probability density function of the form $f(\mathrm{x} ; \mu, \sigma)=\exp$ $\left(-[\ln x-\mu]^{2} / 2 \sigma^{2}\right) /\left(x \sigma[2 \pi]^{1 / 2}\right)$ (where $\mu$ and $\sigma$ are the mean and standard deviation, respectively), thus making it possible to do a quantitative comparison of the SEM pictures and consequently enabling us to compare the spray-dried samples. The powders are formulated after carefully selecting a wall material/nanoemulsion ratio where no aggregates are formed so that the sample remains in powdered form even after drying. For conventional imaging in SEM, the sample needs to be fixed on a carbon support followed by coating with a conductive metallic layer, which makes the particles appear as if they are aggregated. However, the advantage of the software used for analyzing the size distribution lies in its ability to distinguish single particles even when they look aggregated. The originality of this approach lies in the possibility of quantitative analysis of the SEM pictures and thus of sample comparison. Each specimen of wall material encapsulating the nanoemulsions was spray-dried twice and the SEM measurements for each one were performed on three distinct SEM carbon supports. For each given experiment, a representative picture of the SEM results obtained was selected and reported in figures accompanying this paper.

\section{Stability study of vitamin E acetate in microparticles using HPLC}

HPLC was used (Pump LC-126, detector LC-168, and injector LC-508; Beckman-Coulter, Fullerton, CA) to follow 
the stability and integrity of vitamin E acetate encapsulated in the spray-dried microparticles. The operational conditions were defined as: stationary phase, column $\mathrm{C} 8$, length $0.125^{\circ} \mathrm{m}, \varphi 4.0^{\circ} \mathrm{mm}$ (CC125/4 Lichrospher 100-5 RP-8; Macherey-Nagel, Düren, Germany); mobile phase, a mixture of $50 \mathrm{vol}$ of acid aqueous phase $(\mathrm{pH} \mathrm{2.3)}$ ) and $950 \mathrm{vol}$ of a mixture of $85 \%$ methyl alcohol and $15 \%$ isopropanol; flow rate $1.2 \mathrm{~mL} /$ minute; and a spectrophotometer operated at $285 \mathrm{~nm}$ and injection volume $20 \mu \mathrm{L}$. The reference samples of vitamin $\mathrm{E}$ acetate were selected at a concentration of $89 \mu \mathrm{g} / \mathrm{mL}$.

Quantification of the vitamin E acetate trapped in the spray-dried microparticles was performed by collecting an amount of powder with a vitamin acetate content identical to that of the reference sample. The powder was then dissolved in the mixture of water and isopropanol. However, in accordance with the wall material properties, different ratios between water and isopropanol were used, adapted to the wall materials. The amount of vitamin E acetate was determined at initial time (ie, immediately after the spray-drying process) and then once a week for each wall material over 3 months. Each specimen of wall material was spray-dried twice and the HPLC measurements for each powder were carried out in triplicate.

\section{Results and discussion Pure wall material microparticles}

First, all the different wall materials were individually spray-dried in order to evaluate their potential influence on the spray-drying process and on the microparticle properties, ie, size, polydispersity, and morphology. The samples were spray-dried at $15 \mathrm{wt} \%$ in water before processing (a representative concentration). The SEM pictures are presented in Figure 1, including the quantitative study of the size maxima and standard deviation values. These latter values are reported in Figure 2.

The results are not only significant for size distribution and polydispersity, but also for particle shape and morphology, which are closely linked to the interface properties of the compounds and to the spray-drying process. The first observation shows that the microparticle sizes are quite small, generally $1-4 \mu \mathrm{m}$. Furthermore, fluctuations of the maxima between different species are relatively reduced and not significantly different. However, differences do exist, and could be due to the surfactant properties of the polymers, ie, gum arabic, whey protein, maltodextrin, and polyvinyl alcohol, giving rise to smaller particles, whereas Kleptose, Nutriose, Cleargum, and Lycoat produced bigger ones.
The SEM pictures reveal significant differences in particle morphology. Although the samples appear globally homogeneous regardless of the materials used and the microparticles show smooth surfaces and spherical geometry, some of them (eg, Figures 1B, 1C, 1D, 1F, and $1 \mathrm{G})$ show intense invaginations, with a shape resembling a "deflated ball". To explain this result, an interesting parallel can be drawn between these deflated shapes and the global microparticulate sizes, in that the deflated shapes tend to correspond to the bigger particles. This is understandable because before drying all the wall material concentrations in water were the same and the droplets began to dry at their periphery. Thus, the formulations producing bigger sprayed droplets preferentially generate microparticles with an "empty" core, with a "deflated ball" morphology. This is clearly illustrated by the hydroxypropyl beta cyclodextrin particles (Kleptose) in Figure 1C, in which the bigger specimens have shapes with very thin shells. These particular morphologies appear linked to the size of the sprayed droplets, (ie, after spraying and before drying) and thus to the surface properties of the wall material solutions. Conversely, polyvinyl alcohol, known for its surfactant properties, forms spherical microparticles (Figure 1H). The picture also shows the presence of polymer "wires" that physically link the particles, their formation being influenced by interface phenomena and low surface tensions.

\section{Influence of wall material concentration}

This series of experiments was designed to observe the effect of the polymer concentration in the solution on the properties and morphology of the spray-dried microparticles. We thus studied the representative case of gum arabic solutions at $5,10,15,20$, and $30 \mathrm{wt} \%$. The results are presented in Figure 3, including the quantitative study of the size maxima and standard deviation values. Sizes and standard deviations appear very similar in all the concentrations, ranging from 1.5 and $2.0 \mu \mathrm{m}$, with standard deviations from 0.8 and $1.6 \mu \mathrm{m}$. However, there is a significant difference in the samples as regards global aspect, particle shape, and homogeneity. The higher the polymer concentration, the larger the size distribution, reaching huge particle sizes larger than $10 \mu \mathrm{m}$ (shown in Figures 3D and 3E), which are in fact not visible in the statistical analysis because their proportions within the whole population are very small. This is probably due to the higher viscosity of the suspension, which increases with the concentration. Accordingly, the representative wall material concentration of $15 \mathrm{wt} \%$ was chosen for the rest of the experiments. 

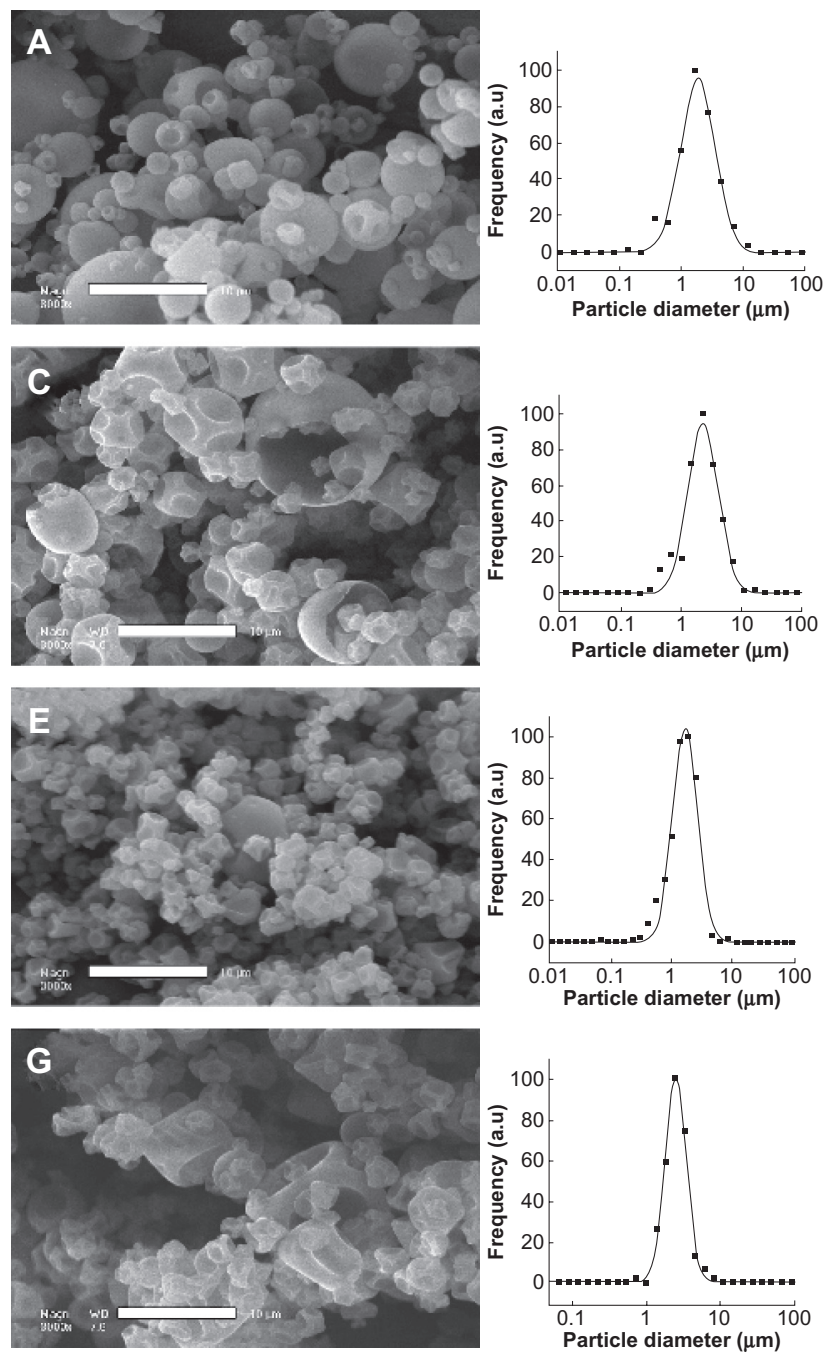
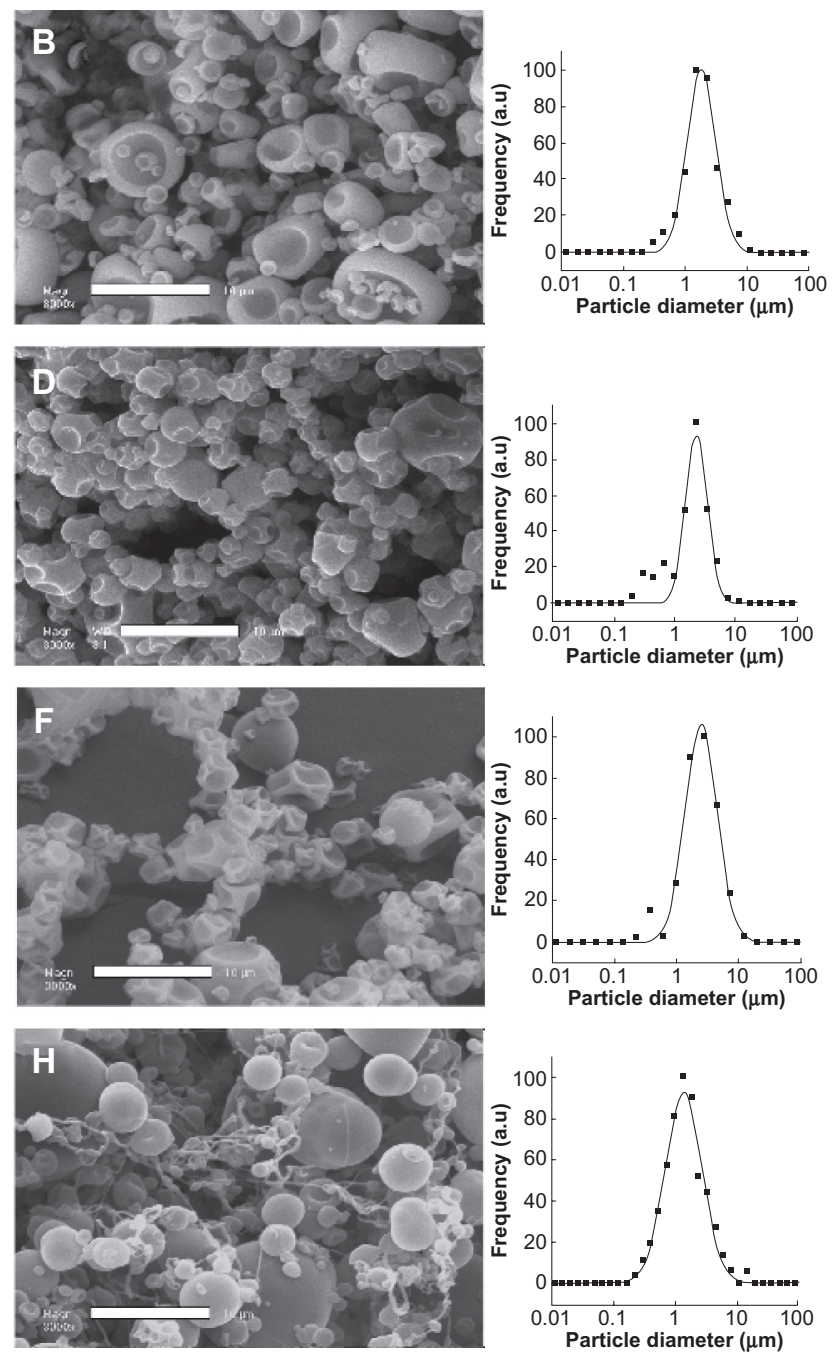

Figure I Scanning electron micrographs of the powders of spray-dried pure wall material microparticles. The wall material concentration in water before processing is fixed at 15 wt\%. (A) whey protein, (B) gum arabic, (C) Kleptose ${ }^{\circledR}$, (D) Nutriose ${ }^{\circledR},(\mathbf{E})$ maltodextrin, (F) Cleargum ${ }^{\circledast},(\mathbf{G})$ Lycoat $^{\circledR}$, and $(\mathbf{H})$ polyvinyl alcohol. Scale bar I0 $\mu$ m.

\section{Vitamin E acetate nanoemulsions}

As described in the Methods section, the nanoemulsification process is characterized by studying the influence of the surfactantto-oil ratio on the size and polydispersity of the nanoemulsions. These results are reported in Figure 4. The general trend, as expected and found with various other systems, ${ }^{14}$ shows a lowering of the droplet size and polydispersity index as the amount of surfactant is increased (ie, an increase of the surfactant-to-oil ratio). The first results highlight the efficiency of the nanoemulsification process: They are all the more significant because the formulation proposed here uses only vitamin $E$ acetate as a hydrophobe, totally substituting any oily compounds generally used in these spontaneous emulsification processes (eg, oleic macrogols or triglycerides). Nanoemulsions with relatively monodispersed droplets (polydispersity index $<0.2$ ), with $\mathrm{d}_{\mathrm{h}}=189 \mathrm{~nm}$, are obtained from a surfactant to oil ratio of $20 \%$. With a surfactant to oil ratio of $40 \%$, the droplet size falls to below $100 \mathrm{~nm}$. In order to ensure efficient nanoemulsion encapsulation of the spray-dried microparticles, the present proof of concept study used nanodroplets below $100 \mathrm{~nm}$. Hence, the chosen value was a surfactant to oil of $40 \%$ (indicated with the arrow in Figure 4), giving rise to nanoemulsions exhibiting a hydrodynamic diameter $d_{h}$ of $84 \mathrm{~nm}$ and a polydispersity index of 0.11 .

\section{Microencapsulation of nanoemulsions}

The production of dried microparticles to entrap the oily nanoemulsion droplets was performed, as described earlier, by spray-drying the nanoemulsion droplets in suspension in an aqueous bulk phase, thereby solubilizing the wall material polymers. An important parameter of the process was the respective proportions of these compounds. The impact of the oil + surfactant/wall material weight ratio on the microparticulate properties, morphology, and size distribution was 


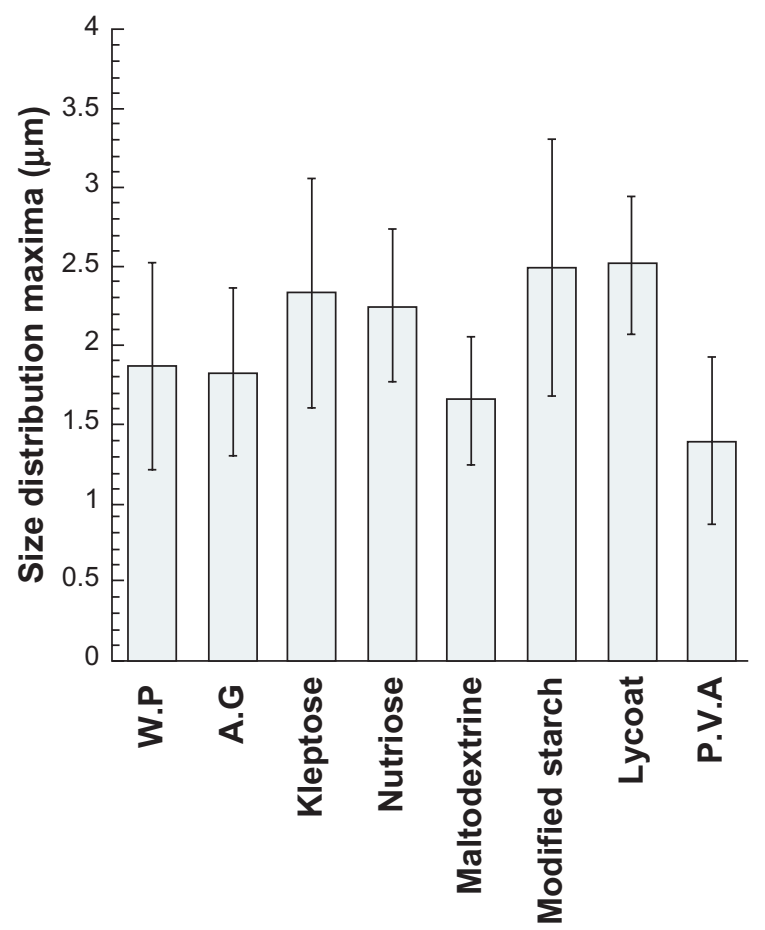

Figure 2 Size distribution values of maxima (curve peaks) and standard deviation of the samples presented in Figure I, corresponding to the microparticles formulated with pure wall materials.

evaluated for the representative case of whey protein. The results are reported in Figure 5, and the quantitative study of the size maxima and standard deviation values are reported in Figure 6. Four different ratios were tested, ie, 1:1, 1:2, $1: 3$, and 1:4, corresponding to vitamin $E$ acetate loadings of $37.5,27.3,21.4$, and $17.6 \mathrm{wt} \%$, respectively.

The samples appear to be very homogenous, generally presenting a similar aspect. When compared with the pure formulations shown in Figure 1A, the first point to observe is the almost perfect spherical shape of the particles. The "deflated" morphology of the particles discussed above is no longer present, now being replaced by spherical shapes and smooth surfaces. This could be due to the global increase of droplet loading before drying, which is doubled with the ratio $1: 1$. Hence, the empty cavities formed with pure wall materials no longer exist, giving way to spherical morphologies. As for the size distribution, a clear difference is observed between the ratios 1:1, 1:2,1:3, and 1:4. The latter presents an outstanding submicronic size, with particle diameters around $500 \mathrm{~nm}$. Looking at this result in terms of interface properties, we can note that not only do the nanoemulsions here show significant surfactant properties, but that the droplet loading is reduced with the ratio of $1: 4$, thus affording a decrease in the particle size. Furthermore, these results were obtained with whey protein, for which each ratio gave rise to powdery
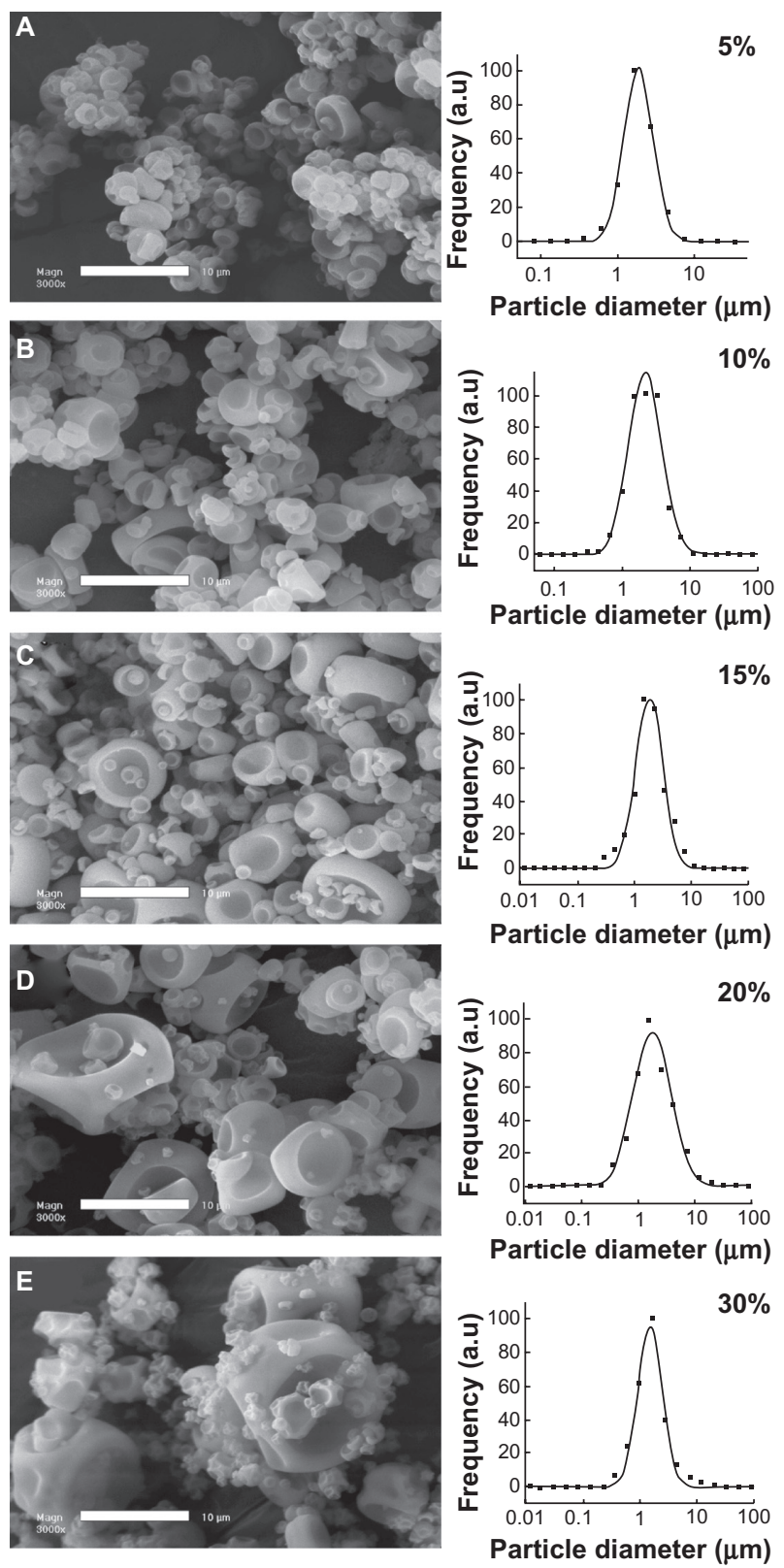

Figure 3 Scanning electron micrographs showing the influence of the wall material concentration on the microparticular size distribution and standard deviation. Wall material is gum arabic. Concentrations are indicated on the pictures. Scale bar $10 \mu \mathrm{m}$.

and homogeneous samples. However, using the other wall materials, this limit fluctuated from 1:1 to 1:4. This parameter was accordingly fixed to 1:4 for the rest of the study.

The next series of experiments concerned the actual process of nanoemulsion microencapsulation. Wall materials were spray-dried along with surfactant alone, vitamin $\mathrm{E}$ acetate alone, and both the surfactant and the vitamin E acetate formulated as a nanoemulsion. For each experiment using surfactant alone and vitamin E acetate alone, the compound amounts strictly corresponded to those required for nanoemulsion formulation. The aim of these experiments was 


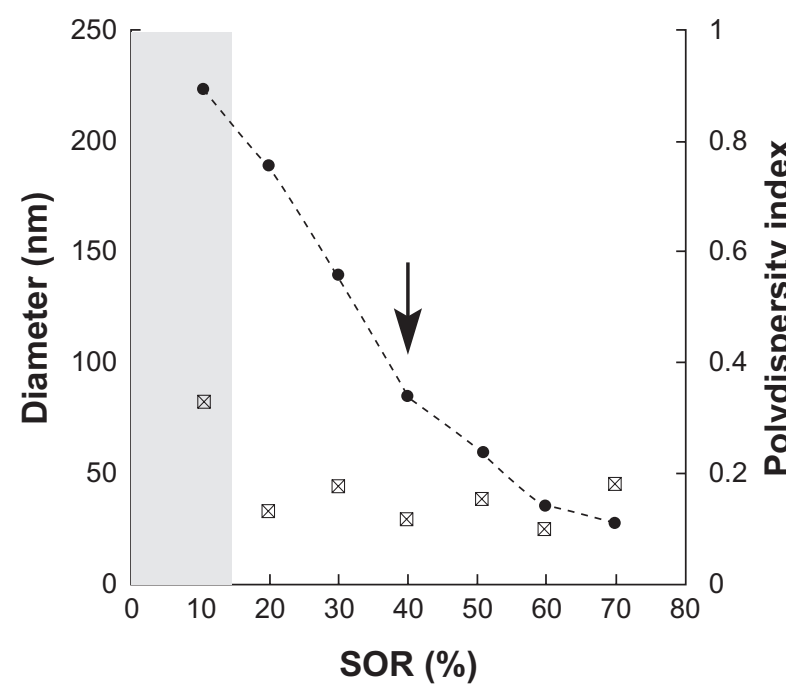

Figure 4 Characterization of the spontaneous nanoemulsification process. Surfactant is Cremophor $^{\circledR}$, oily phase is vitamin E acetate. The hydrodynamic diameter (filled circles) and the polydispersity index (white squares) are plotted against the surfactant/oil weight ratio. The gray part indicates that the criteria for quality of the polydispersity index are not met, the suspension cannot be considered a nanoemulsion. The arrow shows the formulation selected for microencapsulation.

to see whether the nanodispersed forms themselves could have an influence on the spray-drying process. The results are presented in Figure 7 for representative wall materials, including quantitative study of the size maxima and standard deviation values for gum arabic (Figure 7B), whey protein (Figure 7C), and Kleptose and Nutriose (Figure 7D), and are summarized in Figure 8.

Here, the first observation concerns the morphology of the microparticles as a function of the compounds added to the wall materials. As discussed earlier, the "deflated" aspect of the particles is generally inhibited by the presence of the oily phase or nanoemulsions, but, conversely, it seems to be enhanced by the
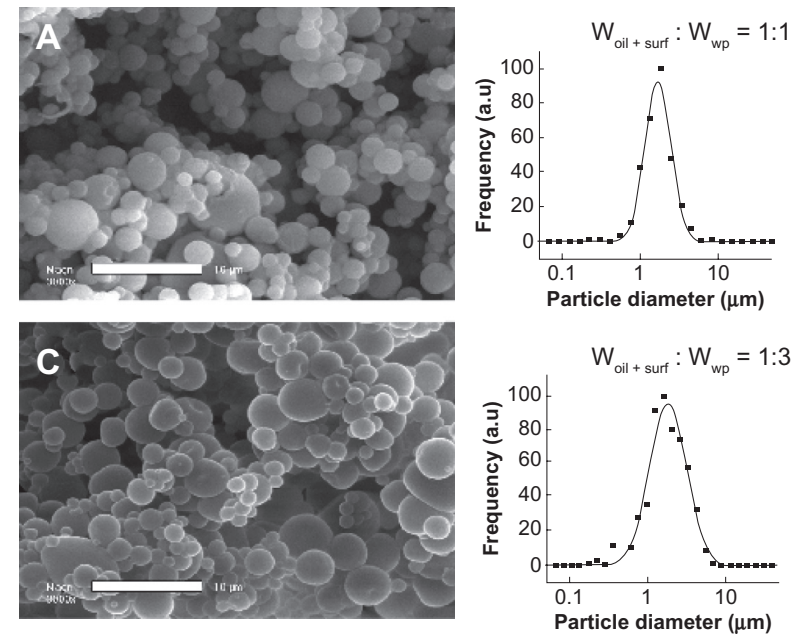

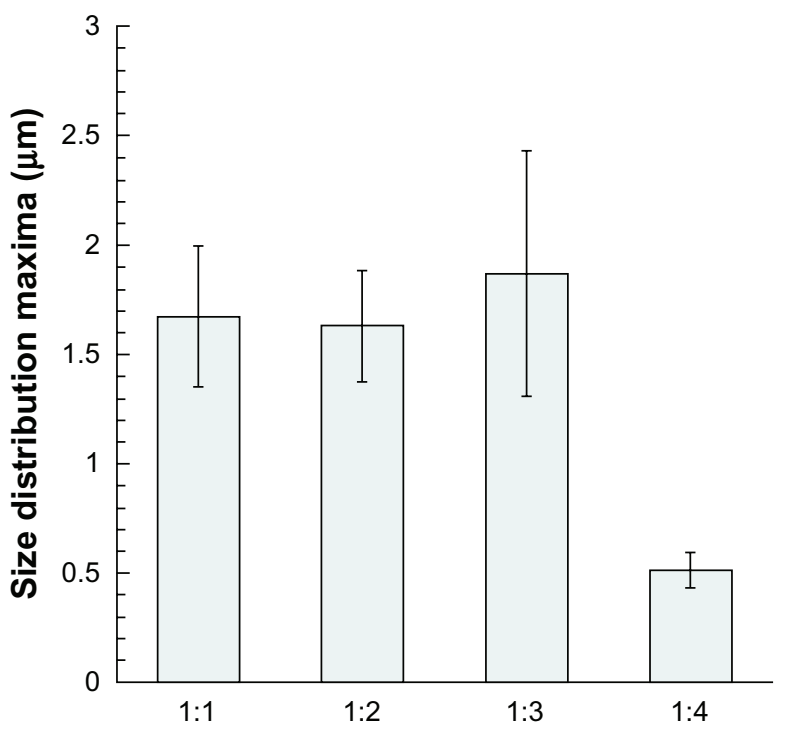

Figure 6 Size distribution values of maxima (curve peaks) and standard deviation of the samples presented in Figure 5, corresponding to the microparticles encapsulating vitamin $\mathrm{E}$ acetate nanoemulsions.

surfactant (except with the whey protein for which this deflated effect appears less pronounced). The wall material + vitamin $\mathrm{E}$ acetate alone systems provide particularly smooth surfaces. This series of experiments also revealed interesting results as regards the formulation process itself. Indeed, for a similar amount of surfactants using the wall material + surfactant alone system and the wall material + nanoemulsion system, the resulting microparticle sizes were significantly different, especially for gum arabic and whey protein. However, even if this result is not as apparent with Kleptose and Nutriose, the global trend highlighted in Figure 8 shows that generally the size is slightly reduced with the wall material + surfactant alone system and slightly increased for the wall material + vitamin E acetate alone system.
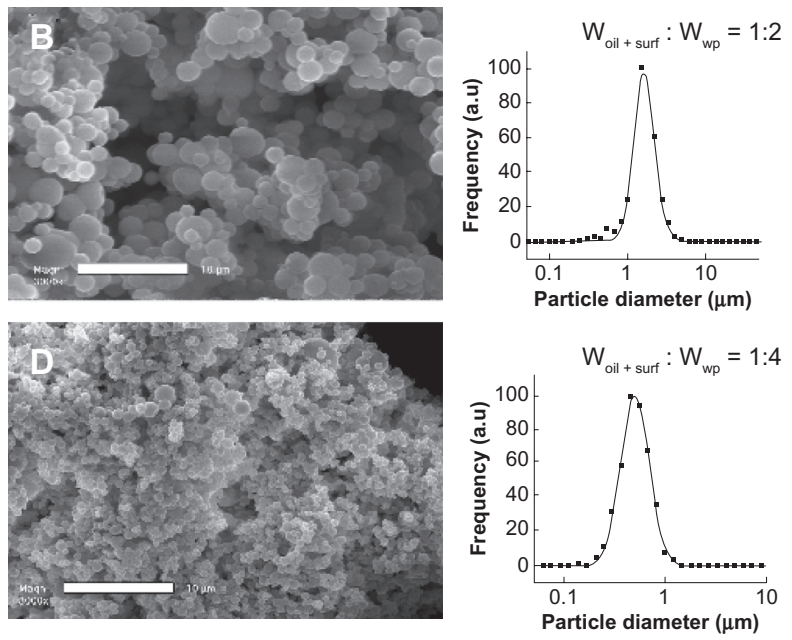

Figure 5 Microencapsulation of vitamin E acetate nanoemulsions: influence of the oil + surfactant/wall material weight ratio on microparticulate properties, morphology, and size distribution. Wall material is whey protein. Scale bar $10 \mu \mathrm{m}$. 


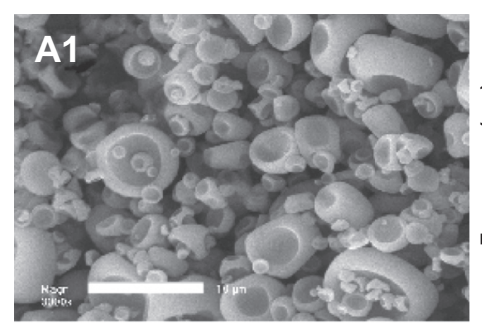

Pure WM (A.G.) $15 \%$
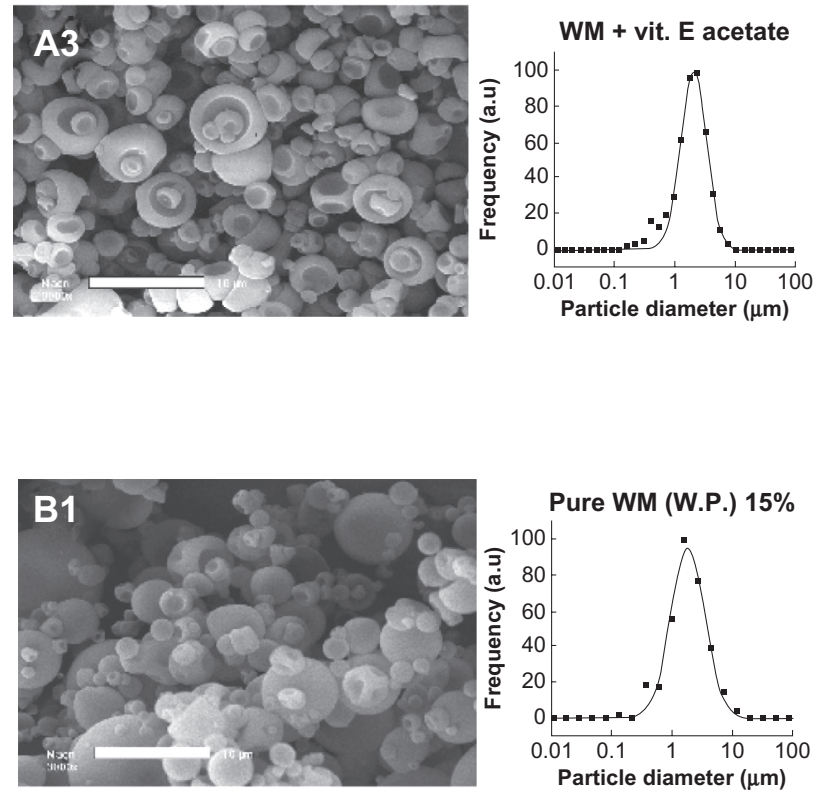

Pure WM (W.P.) $15 \%$
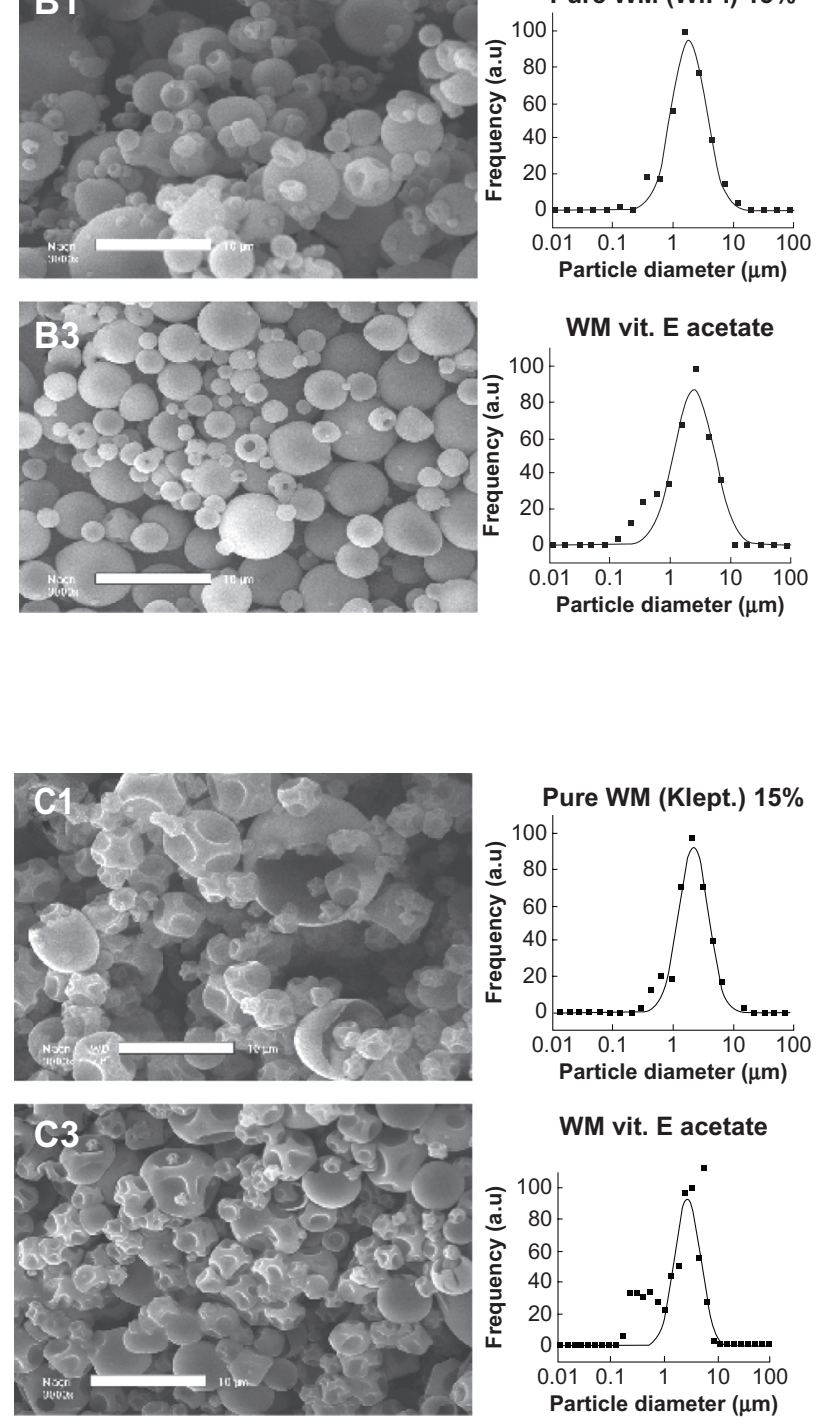
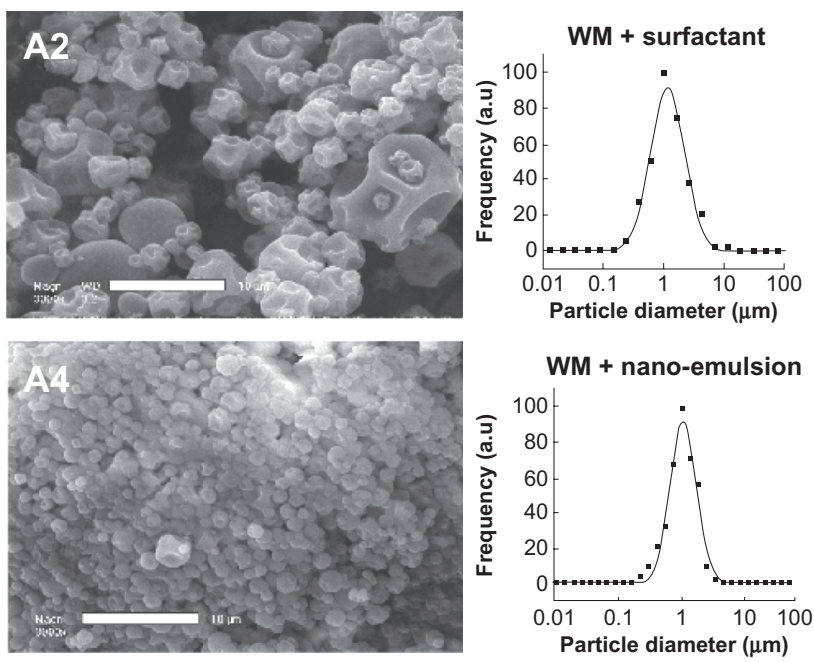
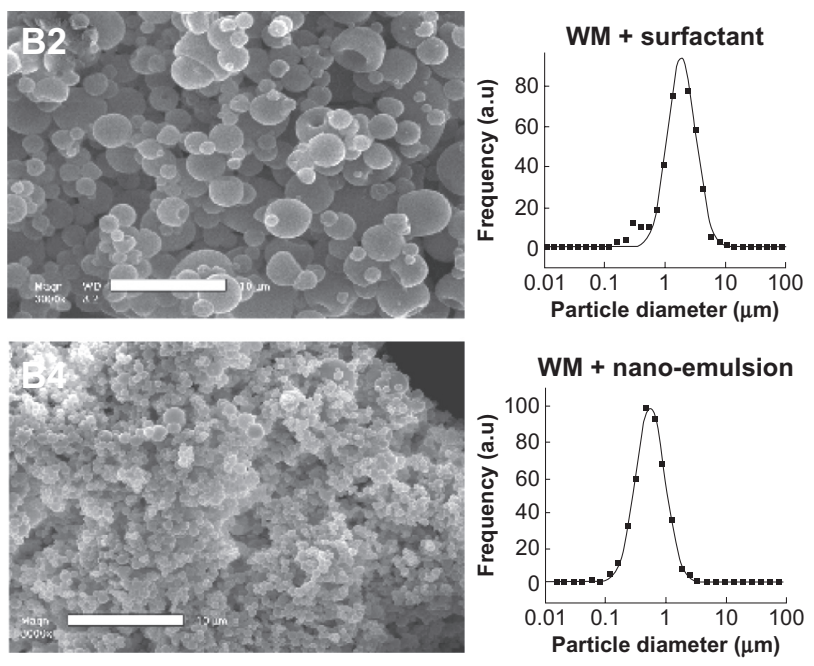

Figure 7 (Continued)
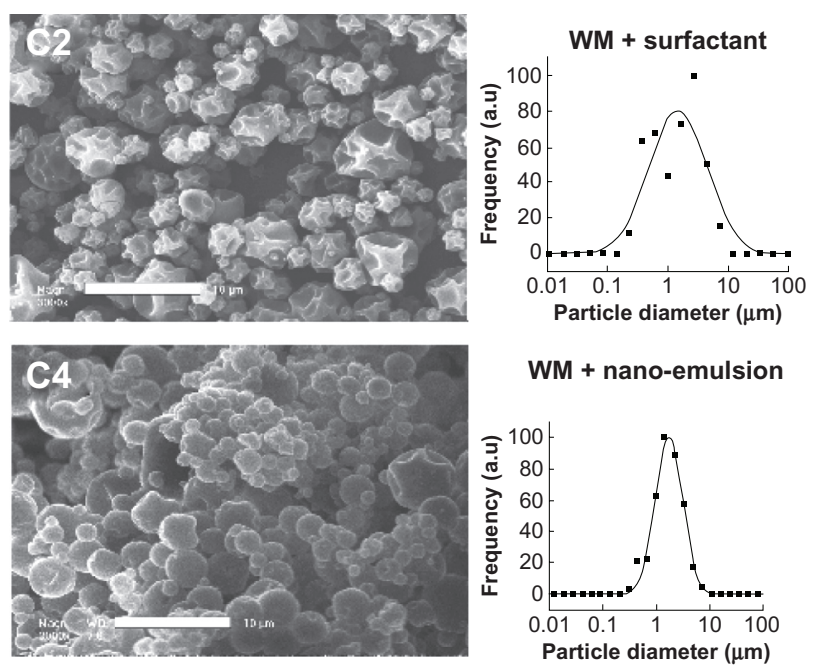

WM + nano-emulsion

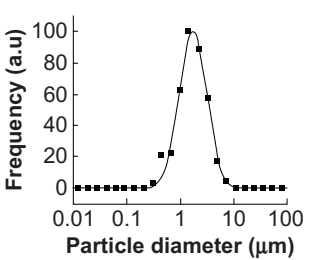



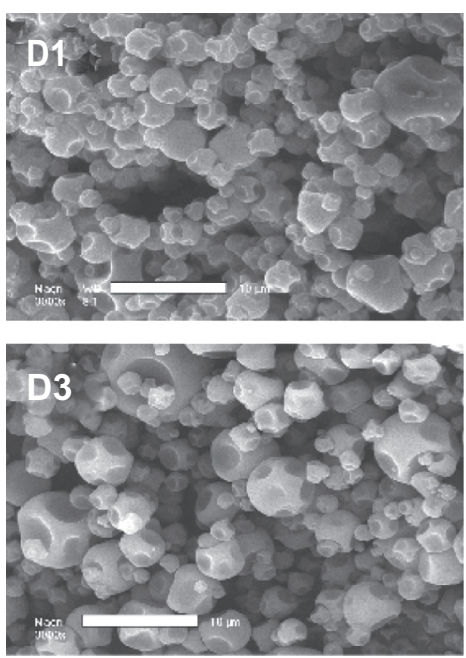

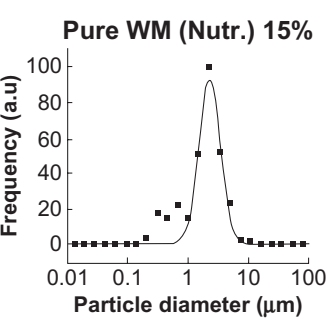

WM vit. E acetate

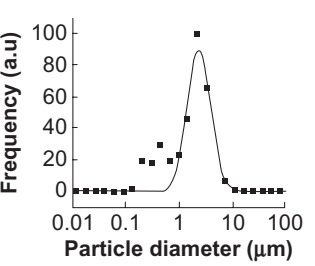

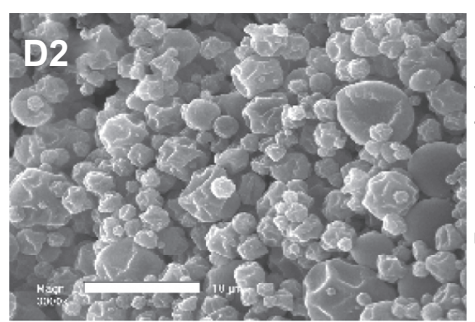
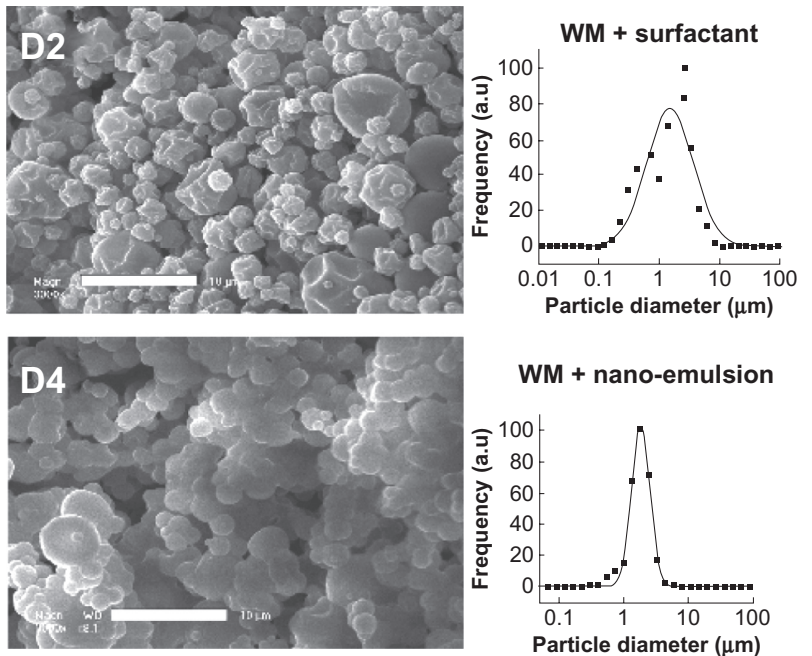

WM + nano-emulsion

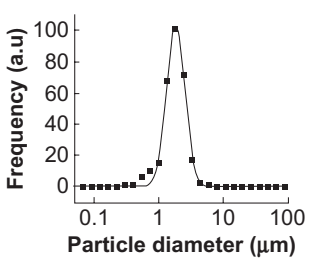

Figure 7 Microencapsulation of vitamin E nanoemulsion acetate. (A) gum arabic, (B) whey protein (C) Kleptose ${ }^{\circledR}$, and (D) Nutriose ${ }^{\circledR}$. Scale bar $10 \mu \mathrm{m}$.

These results corroborate the idea that nanoformulated materials can present more enhanced effects than those induced by nonformulated compounds. In our case, only the surfactant is likely to affect the interface phenomena governing the spray-drying process. This can be illustrated by comparison of the wall material + surfactant alone system and the wall material + nanoemulsion system. This suggests that some of the nanoemulsion droplets are "trapped" at the water/air interface, reducing the surface tension even more

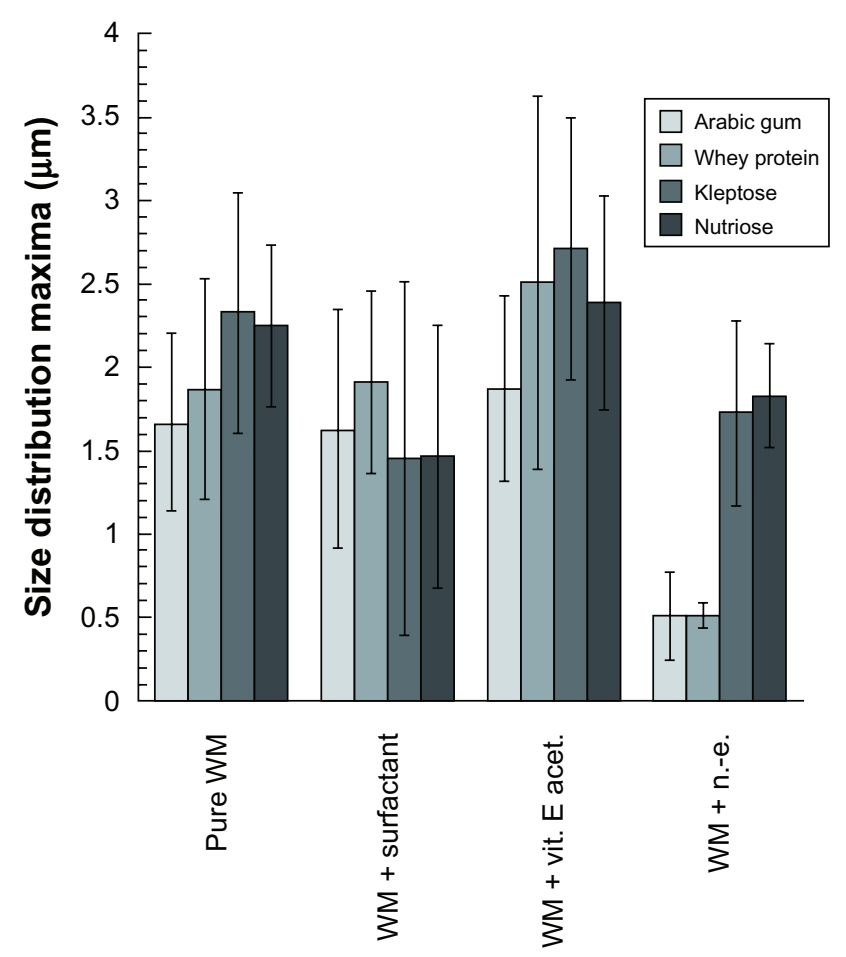

Figure 8 Size distribution values of maxima (curve peaks) and standard deviation of the samples presented in Figure 7. than with the surfactant alone, and giving rise to smaller droplets.

\section{Nanoemulsion release from the spray-dried microparticles}

One objective of this study was to prove that it was possible to microencapsulate nanoemulsion droplets in order to propose new solutions for the delivery of nanoemulsions, thus allowing enhanced absorption of the encapsulated compounds. The microencapsulation of nanoemulsion droplets also requires that, once entrapped in the dried microparticles, the nanoemulsion oil droplets conserve their size and individual nature. This can be checked by the redispersion of the dried powder in water. The polymer is rapidly solubilized due to the huge specific surface of the powder and, if kept intact during the process, the nanoemulsion droplets can be redispersed in water. This is exactly what occurred with all our samples of microparticles encapsulating nanoemulsions. Their resolubilization in water allowed redispersion of the nanoemulsion droplets. Because all the wall materials used are soluble in water, the times within which the nanoemulsions are redispersed in water appear to be relatively short, ie, a few minutes. They will depend on both the water/particle ratio and the nature of the wall materials (ie, on the kinetics of the wall material solubilization in water). For instance, for a given amount of powders mixed in water $(10 \mathrm{wt} \%)$, redispersion of the nanoemulsions was achieved for the different WM as follows: gum arabic about 5 minutes; whey protein about 5 minutes; Kleptose about 3 minutes; and Nutriose about 3 minutes. After redispersion, the samples, like typical nanometric dispersions, were translucent and their characterization was performed by 
Table I Nanoemulsion size distribution, before mixing with wall materials ("raw nanoemulsions"), mixed with wall materials before spray-drying, and after spray-drying when the dried particles are resolubilized in the same water volume

\begin{tabular}{|c|c|c|c|c|c|c|}
\hline \multirow[t]{2}{*}{ Wall materials } & \multicolumn{2}{|c|}{$\begin{array}{l}\text { Raw } \\
\text { nano-emulsion }\end{array}$} & \multicolumn{2}{|c|}{$\begin{array}{l}\text { Nano emulsion + WM before } \\
\text { spray drying }\end{array}$} & \multicolumn{2}{|c|}{$\begin{array}{l}\text { Nano emulsion + WM } \\
\text { after spray drying }\end{array}$} \\
\hline & $\mathrm{d}_{h}(\mathrm{~nm})$ & PDI & $\mathrm{d}_{h}(\mathrm{~nm})$ & PDI & $\mathrm{d}_{h}(\mathrm{~nm})$ & PDI \\
\hline Arabic gum & & & 86.9 & 0.130 & 155.4 & 0.176 \\
\hline Maltodextrin & & & 81.0 & 0.110 & 182.3 & 0.276 \\
\hline Modified starch & & & 82.6 & 0.150 & 168.3 & 0.268 \\
\hline Whey protein & 79.1 & 0.087 & 83.7 & 0.082 & 100.6 & 0.220 \\
\hline Lycoat $^{\circledR}$ & & & 86.9 & 0.148 & 171.3 & 0.252 \\
\hline Nutriose ${ }^{\circledR}$ & & & 80.6 & $0.08 I$ & 166.2 & 0.244 \\
\hline Kleptose ${ }^{\circledR}$ & & & 98.3 & 0.054 & 127.9 & 0.142 \\
\hline
\end{tabular}

Abbreviations: WM, wall materials; PDI, polydispersity index.

dynamic light scattering. The results are reported in Table 1, presenting the hydrodynamic diameter and polydispersity index of the nanoemulsion droplets, just after formulation (called "raw nanoemulsions"), after mixing with wall materials before and after spray-drying, and redispersion in the same volume of water.

To summarize, a comparison of the samples before and after spray-drying showed a significant increase in size, and was generally doubled for all the samples. This results from slight droplet coalescence and can simply be due to turbulence and heat during the spray-drying process. The results also vary in the function of the wall materials, again indicating that the oil/polymer interactions and affinities could play a role in droplet merging. Nevertheless, the average size of the redispersed droplets remained at about $150 \mathrm{~nm}$ and, with a polydispersity index of around 0.2 , such a suspension can still rightly be considered a nanoemulsion. The microencapsulation of nanoemulsions thus appears to have been successful. Taking into account all the results of the present study, a schematic illustration of the microparticulate structure is shown in Figure 9. These multiscaled systems can in fact be used as carriers for nanoemulsions, ensuring their easy manipulation, concentration, and administration.

\section{Stability of vitamin E acetate in the spray-dried powders}

Stability studies were performed on the powders, the results of which are reported in Figure 10. We can first note that, at initial time, the measurements show approximately $100 \%$ of vitamin $\mathrm{E}$ acetate for all the seven wall materials tested.

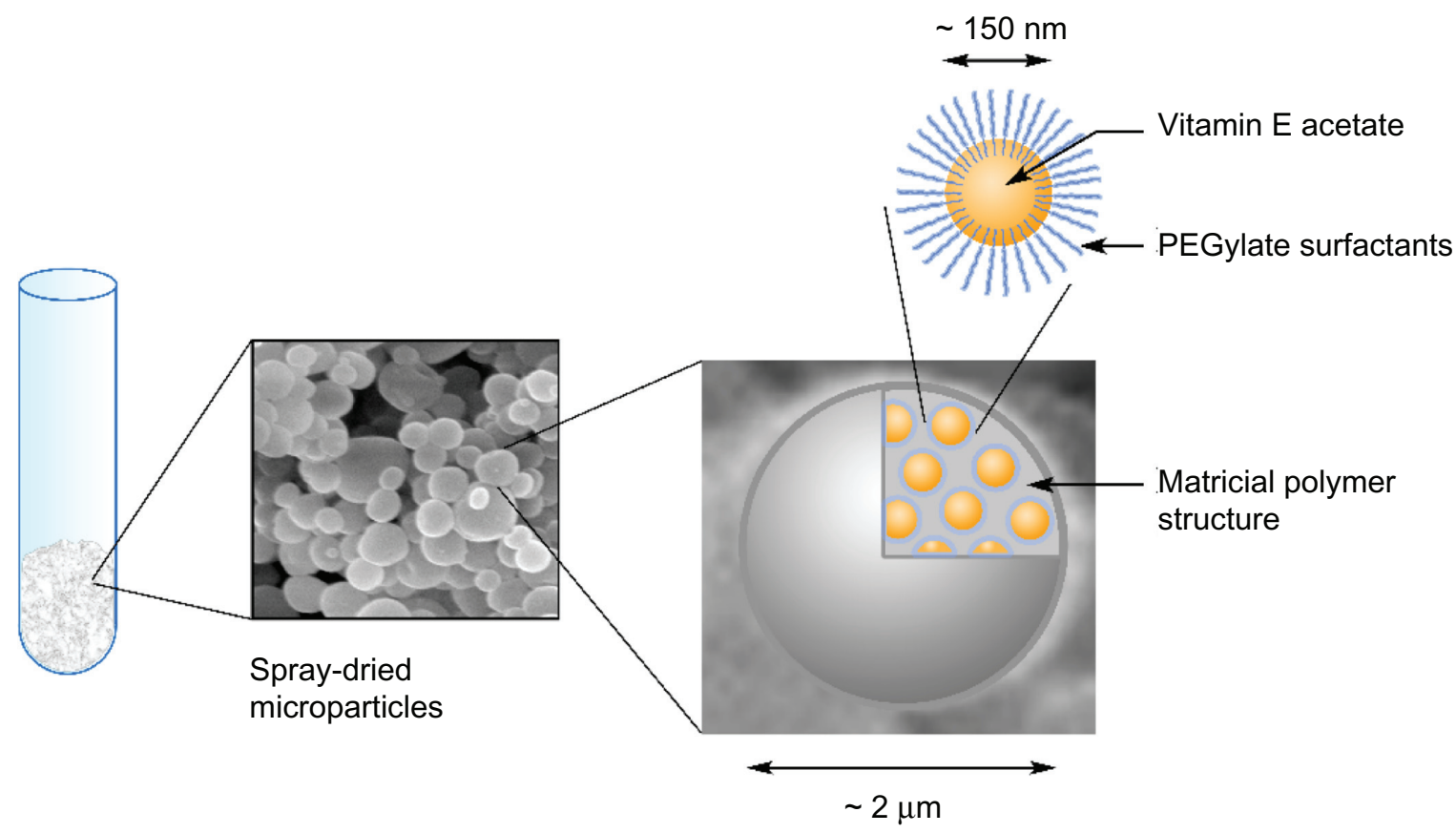

Figure 9 Schematic illustration of the spray-dried microparticles encapsulating vitamin E acetate nanoemulsions. 


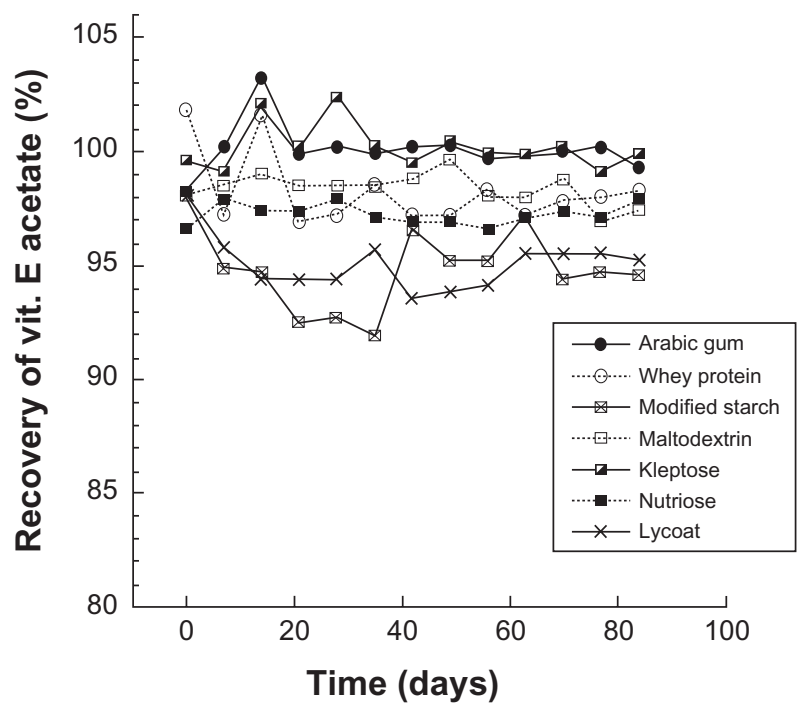

Figure 10 High-performance liquid chromatography measurements monitoring the integrity of the encapsulated vitamin $E$ acetate in the spray-dried powders over time.

This simply indicates that the spray-drying process does not destroy the encapsulated molecules. It is also worth noting that only one peak of vitamin $\mathrm{E}$ acetate was observed for all the wall materials studied and that no other peaks appeared over 3 months. In other words, there was no degradation of vitamin E acetate.

This result is confirmed and corroborated by the overall aspect of the curves in Figure 10, indicating a constant amount of vitamin $\mathrm{E}$ acetate with a recovery of approximately $100 \%$. These results confirm that the spray-drying process can be considered an efficient method for the microencapsulation of nanoemulsions, ensuring the integrity of the molecules throughout the process, as well as their conservation during storage of the dried product.

\section{Conclusion}

This study proposes a novel technique using a spray-drying process to microencapsulate nanoemulsions. The dried powder obtained consists of multiscaled objects in the form of microparticles, with a size range of around $2 \mu \mathrm{m}$. The present study also demonstrates that these microparticles are able to encapsulate (or more precisely "entrap") nanoemulsion droplets of around $150 \mathrm{~nm}$ in their polymeric matricial structure. The low-energy nanoemulsification method chosen, associated with the gentle form of spray-drying, makes the whole process suited to the encapsulation of sensitive molecules. The model lipophilic molecule tested was vitamin E acetate, encapsulated at around $20 \%$ in the dried powder. We show that the presence of nanoemulsion in the solutions before spray-drying can have a significant impact on the size distribution and morphology of the microparticles. However, the process itself does not destroy the oily nanodroplets, which can be easily redispersed once the powder is in contact with an aqueous phase. HPLC follow-up of vitamin E acetate integrity shows that the molecules remain intact throughout the process, as well as during their conservation in dried form.

\section{Disclosure}

The authors report no conflicts of interest in this work.

\section{References}

1. Jyothi N, Prasanna P, Sakarkar S, Prabha K, Ramaiah P, Srawan G. Microencapsulation techniques, factors influencing encapsulation efficiency. J Microencapsul. 2010;27:187-197.

2. Champagne CP, Fustier P. Microencapsulation for the improved delivery of bioactive compounds into foods. Curr Opin Biotechnol. 2007; 18:184-190.

3. Gharsallaoui A, Roudaut G, Chambin O, Voilley A, Saurel R. Applications of spray-drying in microencapsulation of food ingredients: an overview. Food Res Int. 2007;40:1107-1121.

4. Vehring R. Pharmaceutical particle engineering via spray drying. Pharm Res. 2008;25:999-1022.

5. Grenha A, Seijo B, Remuñan Lopez C. Microencapsulated chitosan nanoparticles for lung protein delivery. Eur J Pharm Sci. 2005; 25:427-437.

6. Pilcer G, Amighi K. Formulation strategy and use of excipients in pulmonary drug delivery. Int J Pharm. 2010;392:1-19.

7. Gomez-Gaete C, Fattal E, Silva L, Besnard M, Tsapis N. Dexamethasone acetate encapsulation into trojan particles. J Control Release. 2008; 128:41-49.

8. Tsapis N, Bennett D, Jackson B, Weitz D, Edwards D. Trojan particles: large porous carriers of nanoparticles for drug delivery. Proc Natl Acad Sci U S A. 2002;99:12001-12005.

9. Lebhardta T, Roeslera S, Uusitalo HP, Kissel T. Surfactant-free redispersible nanoparticles in fast-dissolving composite microcarriers for dry powder inhalation. Eur J Pharm Biopharm. 2011;78: 90-96.

10. El-Aasser M, Sudol E. Miniemulsions: overview of research and applications. J Coat Technol Res. 2004;1:20-31.

11. Solans C, Izquierdo P, Nolla J, Azemar N, Garcia-Celma M. Nanoemulsions. Curr Opin Colloid Interface Sci. 2005;10:102-110.

12. Sonneville-Aubrun O, Simonnet J, L'Alloret F. Nanoemulsions: a new vehicle for skin care products. Adv Colloid Interface Sci. 2004; 108-109:145-149.

13. Anton N, Benoit J, Saulnier P. Design and production of nanoparticles formulated from nano-emulsion templates - a review. J Control Release. 2008;128:185-199.

14. Anton N, Vandamme T. The universality of low-energy nanoemulsification. Int J Pharm. 2009;377:142-147.

15. Anton N, Vandamme T. Nano-emulsions and micro-emulsions: clarifications of the critical differences. Pharm Res. 2011;28:45-53.

16. Jafari S, Assadpoor E, Bhandari B, He Y. Nano-particle encapsulation of fish oil by spray drying. Food Res Int. 2008;41:172-183.

17. Soottitantawat A, Bigeard F, Yoshii H, Furuta T, Ohkawara M, Linko P. Influence of emulsion and powder size on the stability of encapsulated d-limonene by spray drying. Innov Food Sci Emerg Technol. 2005; 6: 107-114.

18. Soottitantawat A, Yoshii H, Furuta T, Ohkawara M, Linko P. Microencapsulation by spray drying: influence of emulsion size on the retention of volatile compounds. J Food Sci. 2003;68:2256-2262.

19. Takeuchi H, Sasaki H, Niwa T, et al. Preparation of powdered redispersible vitamin $\mathrm{E}$ acetate emulsion by spray-drying technique. Chem Pharm Bull. 1991;39:1528-1531. 
20. Takeuchi H, Sasaki H, Niwa T, et al. Redispersible dry emulsion system as novel oral dosage form of oily drugs: in vivo studies in beagle dogs. Chem Pharm Bull. 1991;39:3362-3364.

21. Dollo G, Le Corre P, Guérin A, Chevanne F, Burgot J, Leverge R. Spraydried redispersible oil-in-water emulsion to improve oral bioavailability of poorly soluble drugs. Eur J Pharm Sci. 2003;19:273-280.

22. Dollo G, Le Corre P, Chevanne F, Le Verge R. Bupivacaine containing dry emulsion can prolong epidural anesthetic effects in rabbits. Eur $J$ Pharm Sci. 2004;22:63-70.
23. Mezzenga R, Ulrich S. Spray-dried oil powder with ultrahigh oil content. Langmuir. 2010;26:16658-16661.

24. Li X, Anton N, Arpagaus C, Belleteix F, Vandamme T. Nanoparticles by spray drying using innovative new technology: the Büchi Nano Spray Dryer B-90. J Control Release. 2010;147:304-310.

International Journal of Nanomedicine

\section{Publish your work in this journal}

The International Journal of Nanomedicine is an international, peerreviewed journal focusing on the application of nanotechnology in diagnostics, therapeutics, and drug delivery systems throughout the biomedical field. This journal is indexed on PubMed Central,

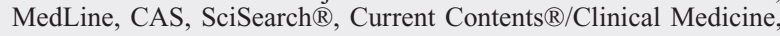

\section{Dovepress}

Journal Citation Reports/Science Edition, EMBase, Scopus and the Elsevier Bibliographic databases. The manuscript management system is completely online and includes a very quick and fair peer-review system, which is all easy to use. Visit http://www.dovepress.com/ testimonials.php to read real quotes from published authors.

Submit your manuscript here: http://www.dovepress.com/international-journal-of-nanomedicine-journal 